$$
\text { RESENHAS }
$$




\title{
Ensaio de Helena: narrativa como travessia da dor e retomada da vida
}

\author{
Helena's tale: narrative as overcoming pain and \\ retaking life
}

fabiana Corréa Prando*

nsaio de Helena, livro de Tatiana Piccardi publicado em 2006, ganhou uma edição bilíngue em 2010 e pode ser compreendido como uma expressão dos efeitos transformadores da linguagem sobre o seu enunciador, no caso a própria autora. Ao relatar o câncer e a morte de sua filha Helena, aos cinco anos, em 1997, Tatiana se apropria e se integra profundamente à história, aceitando seus efeitos avassaladores, irreversíveis e, ao mesmo tempo, promissores. Uma reviravolta que só é possível graças ao desejo de sobreviver que a narrativa projeta e alimenta. Para Tatiana,

Narrar a perda do filho por morte, mais do que compartilhá-la, provocando reações mais ou menos palpáveis, mais ou menos circunscritas ao contexto específico da fala, transforma o enunciador no instante mesmo da sua enunciação. (PICCARDI, 2008, p. 135)

Para a autora, nas narrativas em que a dor é enunciada, existe a possibilidade do que ela denomina "ato de fala curativo". Importante ressaltar que o conceito

\footnotetext{
Mestranda do Programa de Pós-Graduação em Estudos Comparados em Literaturas de Língua
} Portuguesa da FFLCH-USP. 
de cura aqui referido é aquele relacionado ao cuidado de si, ao estabelecimento de uma forma e experiência totalmente novas, e não equivale ao restabelecimento de uma forma anterior. E, mais especificamente, o "ato de fala curativo" merece uma observação mais atenta.

Tal conceituação é cara aos estudos na área de Medicina e Narrativa no Brasil. A teoria dos atos de fala de Austin detalha esse processo, à medida que entende o ato de enunciar como ação constituída por três atos simultâneos: ato de fala locucionário, ilocucionário e perlocucionário:

Locucionário é o ato mesmo de formular o enunciado, para o que o falante utilize os recursos da língua de que dispõe. É o ato de atualizar (pôr em funcionamento em situação concreta) o sistema lingüístico. llocucionário é o ato da comunicação em si, que implica o fazer algo ao enunciar, que pode ser um pedido, uma ordem, uma promessa, distinguindo-se assim o ato ilocucionário do significado do enunciado em si mesmo. Por exemplo, o enunciado "que calor faz aqui!", em dado contexto, pode significar: "por favor, abram a janela!". Esse significado, que muitos consideram equivocadamente como acrescentado, é o ato ilocucionário, e a finalidade específica que lhe é constitutiva no ato da enunciação (pedido, ordem, promessa, etc.) é o que Austin denomina força ilocucionária. Não se trata de acréscimo, pois o ato ilocucionário é inseparável do ato locucionário. Repetindo-se o contexto adequado, "que calor faz aqui!" continuará significando "por favor, abram a janela". Perlocucionário, por sua vez, é o efeito do enunciado no interlocutor, que pode ser previsto pelo falante ou não. A imprevisibilidade dos efeitos da fala projeta o discurso para o novo, para o não- convencional.

Dessa forma, o narrar a perda do filho significa não apenas o conteúdo locucionário do ato, ou seja, a "história" narrada em si mesma, mas o que a narrativa faz no instante mesmo em que é enunciada. Esse fazer é, a meu ver, a força ilocucionária de caráter curativo desse tipo específico de ato de fala. (PICCARDI, 2008, p. 135)

Em Ensaio de Helena (2006), a autora compartilha com os leitores a sua construção de sentido a partir dos fatos, construção essa que a narrativa irá constituir. A interlocução é imprescindível no ato de fala curativo, pois não existe sujeito todo-poderoso que empreenda isoladamente a cura de si. O livro de Tatiana oferece, assim, o contexto favorável e nós, leitores, somos seus interlocutores 
empáticos e constitutivos do ato de fala curativo. Mais do que leitores convencionais, tornamo-nos partícipes de um processo ativo de transformação.

Dessa forma, em Ensaio de Helena, o leitor participa de um ato de fala curativo e sai transformado também. Em tempos de dor profunda, é preciso narrar para ressignificar e viver:

Um dito de autor por mim desconhecido nos diz: "Quando os fios que tecem nossas vidas são violentamente rompidos, somente as mãos do tempo podem cerzir as malhas rasgadas. É preciso dar tempo ao tempo". Eu diria, complementarmente: é preciso dar espaço ao narrar... (PICCARDI, 2008, p. 129)

O livro é dividido em três partes que se complementam e integram, proporcionando ao leitor um mergulho na complexidade da experiência. A primeira parte - "Ensaio de Helena" - relata episódios desencadeados pela doença. Fatos, sentimentos, procedimentos médicos, memórias e reflexões são partilhados com o leitor num fluxo que rompe com a cronologia, favorecendo a intimidade, a empatia. É com muita proximidade e vivacidade que acompanhamos Tatiana e Helena ao longo da narrativa:

Helena brilhou durante toda a festa, mimada e acarinhada por todos. O espaço no carrinho Helena dividia com amigos recém-chegados: bonecas e bichinhos de pelúcia novinhos em folha que, como Helena, não podiam se mexer, mas queriam participar. (PICCARDI, 2006, p. 48-49)

Dr. Ciro, o novo pediatra, olhava com carinho para a Nena enquanto a examinava. Gostei do seu olhar. Não havia pena, ou a compaixão hipócrita dos que antes de tudo pensam: ainda bem que não é com meu filho. Havia, sim, um profundo respeito pelo difícil caminho que aquela criança deveria percorrer. (Ibid., p. 25) "O senhor não acredita em Deus? Não tem fé?" "Filha, sou muito religioso, mas na igreja, aqui preciso ser objetivo." "Pois eu acredito em milagres. Gostaria que o senhor fosse à festa que daremos para Helena quando ela se curar. Será a maior festa jamais vista." "Filha, Deus sabe como eu gostaria de estar lá." (Ibid., p. 18-19)

"Diário" - segunda parte do livro - traz uma perspectiva neutra, objetiva, muito próxima ao que se convencionou chamar de "olhar clínico" em relação aos acontecimentos relatados na primeira parte da obra. Em quatro páginas rigoro- 
samente datadas de 01/02 a 20/07/97, acompanhamos o registro da evolução da doença da pequena Helena. Observado o conjunto da obra, a segunda parte faz um contraponto perfeito à primeira em que o tempo psicológico, das emoções é privilegiado. O leitor tem, assim, a real dimensão da intensidade de vida compreendida em um intervalo de tempo tão estreito:

1/2/97 - constatação do estrabismo; estado geral da Nena é bom

$4 / 2$ - consulta com oftalmologista

6 - primeira ressonância magnética; constatação do tumor no troncocerebral

7- consulta com neurologista (expectativa de vida: 18 meses... sumiu o chão sob nossos pés, cirurgia descartada, indicação para radioterapia)

8 - consulta com oncopediatra (vamos lutar! - começamos a construir algum chão). (lbid., p. 55)

A terceira parte - "Próxima história" - retoma e transcende a primeira, colocando em destaque a imaginação, essa grande mediadora da jornada humana. Tatiana escreve neste último capítulo a história que ela mesma contou à Helena momentos antes de sua morte, na UTI do hospital.

Helena, a mamãe vai te levar a um lugar muito bonito, através da nossa imaginação... Esqueça esses tubos incômodos que te ligam a um tipo de vida que não interessa mais. Ouça esta música que gravei pra você. É com ela que poderemos chegar ainda mais rápido a esse lugar de que Ihe falo, esse lindo lugar! (Ibid., p. 59)

A mesma Tatiana, que vive e escreve sua experiência em Ensaio de Helena, elabora:

A Coisa horrenda foi vista e sentida, só será afastada para que a vida regular tome seu curso após a elaboração da perda no nível do imaginário, que tece os fios que reposicionam esses pais na esfera da trivialidade que mascara o buraco negro do Real. Quando isto é finalmente feito, termina o luto. (PICCARDI, 2008, p. 134)

Enfrentar a impossibilidade, viver na companhia da "coisa horrenda" e voltar para contar que sim, existe vida após a morte, são os pilares de Ensaio de Hele- 
na. Um episódio vivido, que nos lembra que a morte e o morrer nos constituem. Uma narrativa cerzida pelo livre fluxo de imagens e memórias, pela descrição fiel aos procedimentos médicos e pela construção de metáforas metafísicas sobre a morte.

Inestimável também é a contribuição da obra para os estudos de Literatura e Medicina. Sua abordagem ultrapassa uma das propostas inaugurais da área: o investimento na competência narrativa dos profissionais direta ou indiretamente ligados aos cuidados médicos. O leitor encontrará no texto de Piccardi uma modalidade muito mais próxima à "ilness narrative" postulada por Kleinman, uma forma pela qual os pacientes modelam e dão sentido aos seus sofrimentos (KLEINMAN, 1998). O mesmo autor ressalta o cuidado, em tais narrativas, em não transformar o sujeito em objeto, o que é plenamente realizado em Ensaio de Helena.

Abordar a doença por meio de uma história transforma o fato em experiência e o que era circunscrito aos limites de um corpo físico individual, pela via da linguagem, torna-se um elo comum. As vulnerabilidades compartilhadas possibilitam empatia.

O livro é um registro valioso de questões fundamentais para os estudiosos de Medicina e Narrativa no Brasil. A autora, pesquisadora da área, imprime sua vivência pessoal e também sua perspectiva à luz das teorias da linguagem. Quantas obras reúnem esse ponto de vista privilegiado? Mais do que a descrição da evolução da doença, o tratamento, as consultas, a autora registra, por exemplo, questões de implicações éticas:

É inumerável a quantidade de visitas, consultas, telefonemas e contatos vários que fizemos até que nos indicassem o Dr. Edson Feldman. Mais inacreditável ainda é que Edson atendia no Einstein, aonde por muitas semanas levamos Helena para as sessões de radioterapia. Lá, nunca havíamos ouvido falar o nome dele, muito menos de sua especialidade (neuroconlogia). O Dr. Ernesto Ziebermann, responsável pela radioterapia, trabalhava em parceria com Edson em vários casos parecidos com o de Helena. Viemos a saber disso muito depois. Descobrimos, finalmente, que nunca nos haviam falado do Dr. Edson porque Helena já era paciente do Dr. Olímpio Dantas. [...]

Demoramos para constatar que todos os médicos da área se conhecem, e bem, apoiando-se mutuamente ou rivalizando-se em vários níveis, não apenas no nível 
estritamente científico. Nesse contexto em que as vaidades facilmente entram em jogo, as indicações que fazem uns dos outros são restritas e governadas por uma ética bastante estranha, que jamais entenderei. (PICCARDI, 2006, p. 41-42)

Pelo relato da autora é possível também perceber a importância do cuidado médico nos momentos em que não há nada "médico" acontecendo...

Helena dormiu muito bem toda a noite. O Dr. Marco Antonio veio vê-la. Foi uma bênção a presença do Dr. Marco em nossas vidas dali para a frente. Objetivo sem perder a sensibilidade, foi o único médico que nos acompanhou até o final. 0 Dr. Marco estava no quarto comigo e com a Nena quando Mauro chegou da rua, aonde teria ido a pretexto de resolver qualquer problema trivial. Chegou com a cabeça totalmente raspada!! Os olhos de Helena brilharam de alegria ao perceber o alcance daquele gesto do pai. Dr. Marco e eu, meio rindo e meio chorando, perdemos a noção do tempo observando aquela cena pouco comum: pai e filha, juntos e carecas, debruçados num leito de hospital, entretidos tateando um na cabeça do outro os toquinhos pontiagudos de cabelo que despontavam com incrível velocidade! (Ibid., p.52)

O próprio ato de narrar, em si, opera a elaboração da intensa experiência vivida. O distanciamento necessário para a elaboração do texto, na escrita de Ensaio de Helena, não deixou os fatos menos tensos ou realistas, mas permitiu a objetividade necessária à transformação de uma dor depressiva em uma dor solidária e transformadora:

Difícil digerir a ideia de ver o nome de minha filha transformado em nome de associação. Um nome que não mais traduzirá seu rosto lindo, mas será conhecido por tantos quanto o ouvirem, daqui para a frente, como um grito de socorro. Com o texto do estatuto, em uma das mãos e uma xícara de café na outra, sentada no banquinho da cozinha, naquele canto escondido em que todos os dias de manhã, solitária, completo a oração que logo cedo, na cama, o despertador me impede de concluir, vislumbro, num horizonte lindo, num amanhecer como poucos, a figura de minha filha crescendo, crescendo. (Ibid., p. 53) 
Embora a doença seja um fenômeno biológico e material, a resposta humana a esse evento não é biologicamente determinada. $\mathrm{O}$ ato de narrar permite-nos vislumbrar a singularidade de cada caso.

A importância do livro de Tatiana como relato de enfrentamento é o seu caráter ativo. $O$ passado foi compreendido e ressignificado e inaugurou uma nova realidade a partir da dor que, em discurso, deixa de ser causa de uma ação para se tornar a ação em si mesma. Algo muito concreto foi possível a partir desse relato, a AHPAS - Associação Helena Piccardi de Andrade Silva, entidade social sem fins lucrativos criada para propiciar maior qualidade de vida a jovens pacientes carentes com câncer, através da oferta de transporte especializado aos hospitais durante os meses de tratamento. Os valores arrecadados com os direitos autorais do livro Ensaio de Helena são destinados integralmente à AHPAS.

Mais do que deslocar a pessoa das margens para o centro de sua própria história, de estabelecer uma ação curativa sobre o sujeito que narra, Ensaio de Helena sensibiliza e inspira leitores e, sobretudo, ajuda efetivamente os jovens e suas famílias em sua desafiante rotina de tratamento do câncer.

\section{Referências}

KLEINMAN, A. The illness narratives: suffering, healing \& the human condition. New York: Basic Book, 1998.

PICCARDI, Tatiana. Ensaio de Helena - Mãe e filha, uma história de amor e luta pela vida. São Paulo: Marco Zero, 2006.

. Relatos de pais enlutados: a dor posta em discurso. Revista Al-

pha, UNIPAM (9):129-137, nov. 2008. Disponível em: <http://alpha.unipam.edu.br/ documents/18125/22328/relatos.pdf>. Acesso em: 28/04/2016

. Transformando sofrimento em narrativa e narrativa em uma nova

vida. Revista Internacional de Humanidades Médicas, UNIFESP, V. 3, N. 1, 2014. Disponível em: <http://www2.unifesp.br/centros/cehfi/documentos/revista_hum_med_ vol3_num1_2014.pdf>. Acesso em: 28/04/2016. 